Gut, 1965, 6, 151

\title{
A review of 436 cases of intestinal obstruction in Ibadan
}

\author{
G. J. COLE \\ From the Department of Surgery, The Queen's University of Belfast
}

EDITORIAL SYNOPSIS The pattern of intestinal obstruction differs remarkably in various parts of the world, and this is a study of the surgical experience in Ibadan where intussusception is a particularly common cause. In Ghana, only 400 miles away to the west, the high incidence of intussusception is not found but is replaced by volvulus of the sigmoid colon. Such studies will be of importance ultimately in unravelling the different aetiologlcal mechanisms which may predispose towards obstruction.

Large in the mind of the general surgeon practising in the tropics, and often in his memory, looms the spectre of intestinal obstruction; and rightly so, for in this disease as in no other, are met the forces of strangulation, sepsis, and the gravest of electrochemical disorganization and water deficiency; and judgment, instinct, and skill in full measure are required for the salvage of many such critically ill patients.

Intestinal obstruction has received the attention of many writers in temperate lands where many long series of case records, carefully analysed, form the groundwork of considerable knowledge on the subject. In the tropics, less has been recorded to date, but there have emerged patterns of the disease that differ in important ways from those we have come to accept. Such studies from Uganda (McAdam, 1961) and Rhodesia (White, 1961) have established the different causes and results of treatment of the complex of illnesses that cause intestinal obstruction in those countries.

In west Africa, and particularly in western Nigeria, this is a disease quite different in its presentation from that seen either in east Africa or even Ghana, only 400 miles to the west, where, for example, volvulus of the sigmoid colon is a common illness affecting young people and caecocolic intussusception is scarcely met, while in Ibadan the former is a rarity and the latter the second commonest cause of obstruction.

One in every 35 operations carried out in the University Hospital, Ibadan, is performed for the relief of intestinal obstruction. These account for one in seven of all emergency admissions to the surgical and obstetric services of the hospital that require operation, and are the commonest abdominal cases so admitted. About 100 such patients are admitted each year, so that they have given extensive experience of the condition in many of its guises; caecocolic intussusception, ascaris obstruction, and obstruction probably following typhoid fever are the most unusual and instructive of these.

The purpose of this survey is to record and analyse this vast amount of information in clinical terms, to uncover some of the patterns of the lesser known illnesses in the group, and thus possible pointers to improving the grave mortality attending the disease in the area concerned, a figure at present of one case in six.

Intestinal obstruction is a symptom of an exceedingly varied collection of illnesses, and is often very difficult to define; for example, most of the patients suffering from intussusception and some with ascaris obstruction in this series had diarrhoea, in spite of a substantial mechanical impedance to the bowel lumen in both; while the majority of those with perforation of the ileum without any such impedance, had complete intestinal obstruction, with vomiting, distension, constipation, and only slightly atypical pain. Indeed, the majority of these underwent laparotomy with a provisional diagnosis of mechanical obstruction.

Strangulated hernia reigns supreme among the causes of obstruction (Fig. 1) as in most series, notably tropical ones; Ibadan departs from the pattern of these, however, in the large numbers of cases of intussusception seen, and the very small numbers of both volvulus of the large bowel and cancers giving rise to obstruction (Table I).

Compared with series reported from north America and the United Kingdom, tropical reports 
TABLE I

ORDER OF FREQUENCY OF DISEASES CAUSING INTESTINAL OBSTRUCTION IN VARIOUS PARTS OF THE WORLD

\begin{tabular}{|c|c|c|c|c|c|c|c|}
\hline & Ibadan & Mulago & Mpilo & Pennsylvania & Minnesota & Massachusetts & London \\
\hline Hernia & 1 & 1 & 1 & 2 & 2 & 1 & 1 \\
\hline Intussusception & 2 & 4 & 5 & 4 & 7 & 4 & 4 \\
\hline Adhesions & 3 & 3 & 3 & 1 & 1 & 2 & 2 \\
\hline Congenital & 4 & 5 & 4 & - & 4 & 9 & - \\
\hline Ileal perforation & 5 & - & - & - & - & - & - \\
\hline Volvulus & 6 & 2 & 2 & - & 6 & 5 & - \\
\hline Ascaris & 7 & - & - & - & - & - & - \\
\hline Cancer & 10 & 6 & 6 & 2 & 3 & 3 & 3 \\
\hline
\end{tabular}

${ }^{1}$ Adhesions and cancer are less important causes in the tropical series, where volvulus is a great deal more common as a whole. Ibadan, however, has an incidence of volvulus comparable with that of the temperate lands, an incidence of cancer much lower than that even in the rest of the tropics; and a very significantly higher rate for intussusception.

show only a fraction of the incidence of cancer, and a much smaller incidence of obstruction due to adhesion. Obstruction of the large bowel alone occurred in just over $1 \%$ of the present series, while in London (Savage, 1960) this figure was about $30 \%$, excluding strangulated hernia.

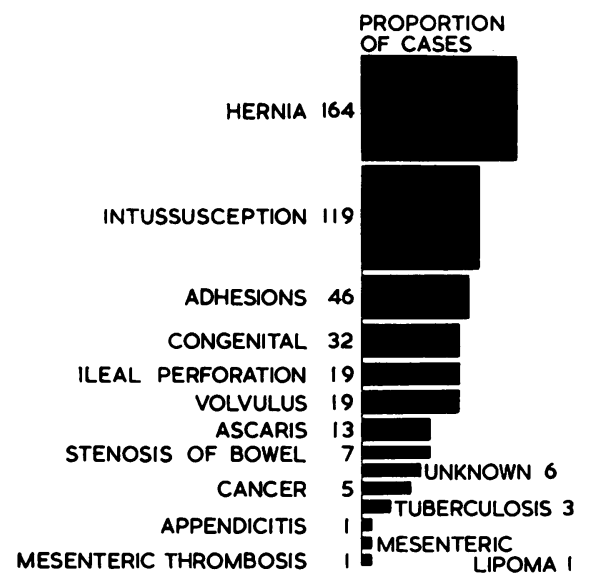

FIG. 1. Lesions causing 436 cases of intestinal obstruction between 1957 and 1962 at University Hospital, Ibadan.

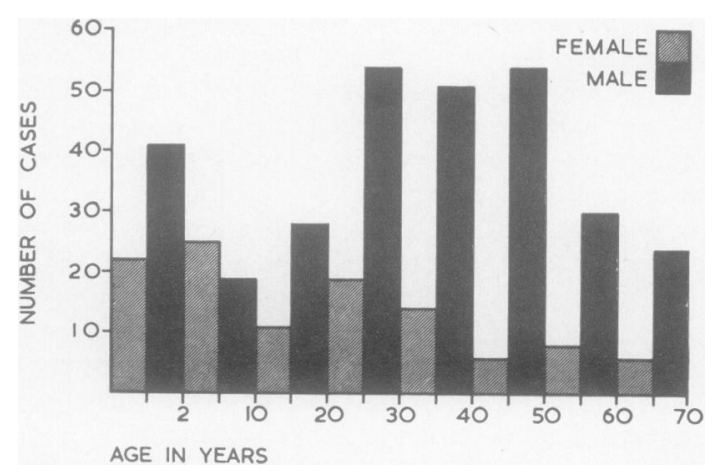

FIG. 2. The age and sex distribution of the series.
The age groups involved (Fig. 2) were primarily the young and the middle aged; congenital lesions and intussusception were responsible for the large numbers of patients younger than 20 years, and after this strangulated hernia, afflicting males in over $97 \%$ of the 164 cases, caused the majority of the large numbers occurring in middle age.

\section{STRANGULATED HERNIA}

These consisted of 156 inguinal, three internal, two femoral, two umbilical, and one obturator hernia. Five patients were female, and these presented the two umbilical and one each of femoral, obturator, and internal hernias.

INGUINAL HERNIA Indirect inguinal hernia was more common than direct, especially on the right side. The site of strangulation was noted only in 32 of these patients, and was at the external and internal rings in equal numbers.

Fourteen of these patients died, though one had widespread pulmonary tuberculosis, and another, an infant, had a sickling crisis under anaesthesia. The main factor in morbidity and mortality was the duration of the illness; gangrene and mortality rose as each day passed, to a figure of $65 \%$ of patients admitted on and after the sixth day.

Direct inguinal hernia was not the benign inconvenience that is often described (Aird, 1957) but in Ibadan was the equivalent of the femoral hernia of the temperate lands; it occurred through a small orifice, with a sharp and firm edge, and the vague bulging of the conjoined tendon that is best treated with a truss was rarely seen: direct hernia was a vicious one, strangulating about half as readily as the indirect, and carrying a $50 \%$ chance of containing gangrenous bowel.

The femoral canal is in most Nigerians very efficiently blocked by a large lymph node (Davey, 1963), which makes it impossible for a hernial sac to pass this way. The enlargement is non-specific, 
and follows the chronic sepsis of the exposed and constantly traumatized lower limb.

Umbilical hernia is very common indeed in children, but seems to be a self-limiting disease, scarcely seen in adolescence. Paraumbilical hernia is a rarity, possibly because of the fine muscular and aponeurotic development of the vast majority of active Nigerians.

The three internal hernias were into a paraduodenal fossa, through a hole in the mesentery of the terminal ileum, and into a paracaecal fossa. In all three the bowel was gangrenous, and the first patient only died due to portal vein and mesenteric artery thrombosis.

This series is analysed in detail elsewhere (Cole, 1964).

\section{INTUSSUSCEPTION}

This is perhaps the most unusual feature of the present series, for in no other does this disease hold second place as a cause of intestinal obstruction. The reason for this is in the large numbers of cases of caecocolic intussusception (Table II), the other

\section{TABLE II}

TYPES OF INTUSSUSCEPTION ENCOUNTERED IN A FIVE-YEAR PERIOD AT UNIVERSITY HOSPITAL, IBADAN

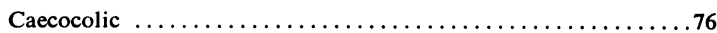

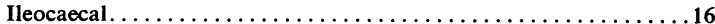

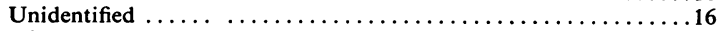

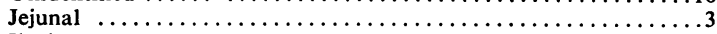

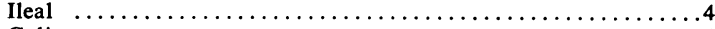

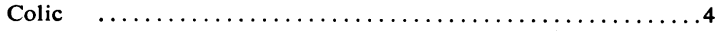

types corresponding approximately to their incidence elsewhere (Fig. 3). The large number of unidentified intussusceptions reflects the uncertainty that often exists in accurately localizing the apex, especially by those inexperienced in this work, who often are called upon to tackle it.

Ileocaecal intussusception occurred 16 times, and only in children under 2 years old. In its symptoms and progress this did not seem to be any different from its counterpart elsewhere, being an acute illness (Fig. 4). A mass was felt in only four of these patients: all presented within eight days of onset of symptoms, and half before the fourth day: resection of bowel was necessary in $31 \%$, and mortality was $19 \%$.

All patients reporting after the fourth day needed resection, but the position of the apex had no relation either to resection or mortality, except that neither occurred if it had not passed the hepatic flexure. In contrast, therefore, to the caecocolic

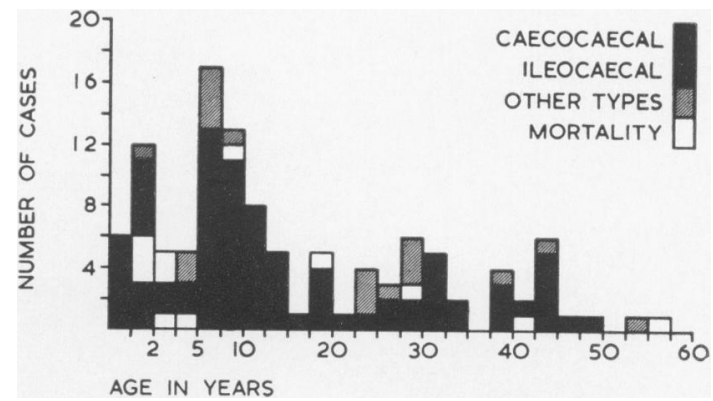

FIG. 3. The types and age distribution of intussusception; the first column in each five-year group denotes female patients, the second males.

ILEOCAECAL

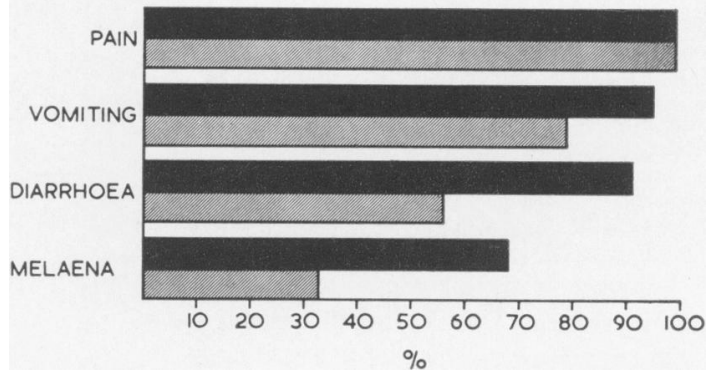

FIG. 4. The symptoms of ileocaecal intussusception compared with those of caecocolic.

variety, duration of illness is the main factor in the outcome.

Jejunal and ileal intussusceptions were met with in small numbers.

Caecocolic intussusception, first described in detail from Ibadan by Joly and Thomas (1954), is the most fascinating disease of this series; it is seen almost exclusively in an area not greater than 100 miles across, in the centre of western Nigeria, and seen there in greater numbers than reported from anywhere else in the world.

It affected mainly young people (Fig. 3). The symptoms (Fig. 4) were much less acute than those of ileocaecal intussusception, and the length of history varied from five hours to nine months, the average being 18 days.

Diagnosis became fairly certain with experience on clinical findings alone, especially the history; radiology was reserved for doubtful cases.

The three main differentials in diagnosis were dysentery, ascaris obstruction, and tuberculous peritonitis. Both the first two cause abdominal cramp and diarrhoea, and especially in children, if a mass is not palpable, decision can be difficult. 


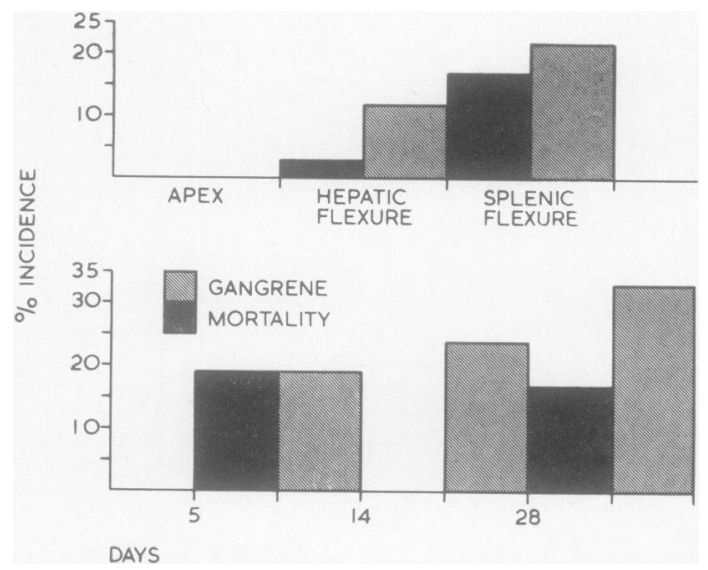

FIG. 5. The relation between gangrene and mortality in caecocolic intussusception and the position of its apex and its duration.

Tuberculous peritonitis was only mimicked by intussusception of long standing.

The incidence of gangrene (seven cases, $9 \%$ ) rose steadily with the distance travelled by the intussusception (Fig. 5).

Mortality (four cases, $5 \%$ ) was confined to patients under 5 and over 40 years of age.

Treatment was operative in all cases.

There were only three recurrences, all in the same patient. One boy, between his twelfth and sixteenth years, had his intussusception reduced every September but one. Each time, his symptoms were admitted to have been preceded by substantial gastronomical excesses.

Experience in Ibadan with intussusception as a whole has confirmed the principle that the higher in the bowel it occurs, the more grave the illness, and the higher the mortality (Fig. 6). Caecocolic intussusception seems to be a different type of disease, with its benign nature and leisurely progress,
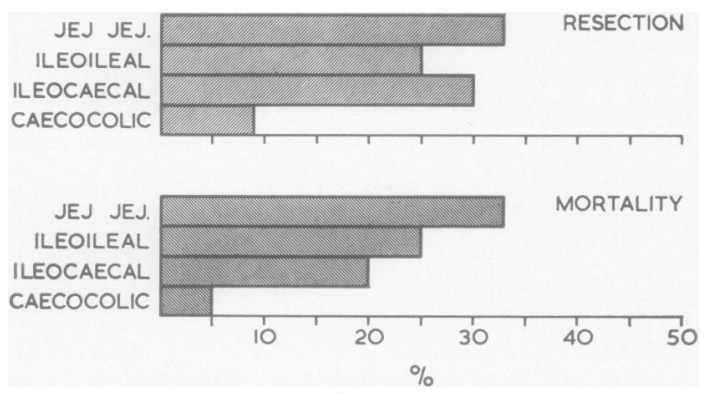

FIG. 6. The rates of resection and mortality in the patient with identified intussusception. carrying only a fraction of the severity and complications of the others.

AETIOLOGY Three intussusceptions were due to salmonella infection, two ileal and one colocolic; with the exception of one case, a 'sclerosing angioma'

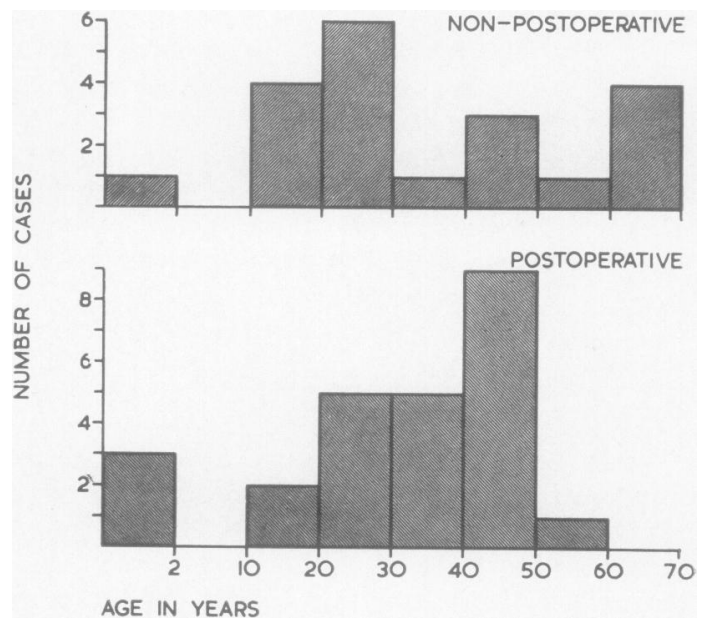

FIG. 7. Age distribution of 46 patients with obstruction caused by adhesions.

of the caecum, the cause or causes of the remainder were not obvious.

Caecocolic intussusception in Ibadan is reviewed in detail elsewhere (Cole, 1964).

\section{BANDS AND ADHESIONS}

Giving rise to 46 cases of obstruction, these were the third commonest cause in the series, though a great deal less common than the first two. Two almost equal groups presented, those following surgery and those not doing so (Fig. 7).

SPONTANEOUS Two-thirds of these 21 patients were females, the majority between 20 and 50 years old, and the youngest 11 days. Two had adhesions confined to the pelvis, two had a band from the small bowel to a Fallopian tube, and the rest bands and/or adhesions affecting the small bowel without obvious connexion with the pelvis. All patients had operation, and three needed resection. There were six deaths, three in women over 50. Fifteen required division of adhesions, and one an ileotransverse anastomosis. One patient of 60 with a four-day history of obstruction died before operation was practicable.

It is most likely that the majority of cases of 'spontaneous' adhesion obstruction followed intra- 
peritoneal sepsis at childbirth. There was no proof of tuberculous infection in any but one patient, though this might well have been the cause of some of the more dense adhesions seen; tuberculosis is a common affliction in Nigeria, though it appears to select the respiratory and skeletal systems much more persistently than elsewhere. The baby of 11 days with numerous adhesions and gangrenous small bowel was thought to have had umbilical sepsis.

These causes leave unexplained at least four male patients with bands, and possibly some females with similar pathology. Experienced surgeons in west Africa not uncommonly meet with cases of purulent peritonitis for which no cause has been clear at operation, and where recovery has followed drainage alone. The cause of these has not been adequately investigated.

POST-OPERATIVE There were 25 patients, 14 female. Obstruction followed operation for strangulated hernia (7), obstetric and gynaecological conditions (5), peritonitis (4), intussusception (3), appendicitis (1), removal of colon (1), and unknown conditions (4). Thirteen of these were due to bands, attaching the small bowel to various parts of the parietes. Nine were due to local adhesions; of these, two were to the back of the wound, and in one the small bowel had been included in a stitch in the peritoneal layer. One case followed plastic peritonitis, and it was not possible to be certain if this was the result of a salpingo-oophorectomy four months previously.

The interval between operation and obstruction (Fig. 8) was accurately known in only 23 cases; in more than half this was less than three months, and in $80 \%$ less than one year. The four remaining patients waited between seven and 10 years to develop obstruction.

Expectant treatment was successful in three cases; 22 needed operation and of these two required resection, one of ileum, and one of ileum and right colon. In the remainder, freeing of adhesions, division of bands, and oversewing of serosa was necessary. There were no deaths in this group.

\section{CONGENITAL}

There were 32 patients, 19 of them female, who suffered intestinal obstruction due to congenital

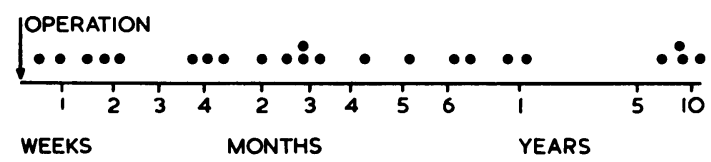

INTERVAL BETWEEN OPERATION AND OBSTRUCTION

FIG. 8. See text. lesions; two of these did not have any symptoms for many years after birth. The lesions were:

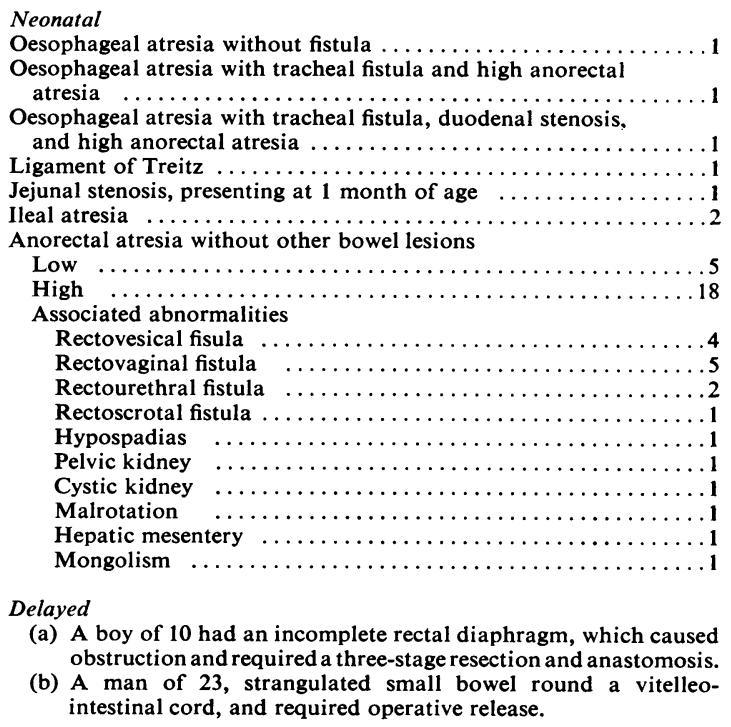

(a) A boy of 10 had an incomplete rectal diaphragm, which caused obstruction and required a three-stage resection and anastomosis.

(b) A man of 23, strangulated small bowel round a vitelleointestinal cord, and required operative release.

Overall mortality was $53 \%$. This high figure was due to many factors, the most significant of which were the incidence of prematurity and underweight, sometimes delay in presenting for treatment, and the high incidence of multiple abnormalities of a severe kind.

Other factors contributing to mortality were: pneumonia in three cases; post-operative peritonitis and pleural abscesses in one: and pyleophlebitis in one.

\section{ILEAL PERFORATION}

Although intestinal obstruction was probably not the most serious component of this illness, it was as often as not the presenting one, and many of these patients were submitted to operation with a provisional diagnosis of mechanical obstruction. It affected mainly young adults (Fig. 9), and outside this age group was a particularly lethal disease.

All patients complained of central abdominal pain, present from one to eight days, the average duration of symptoms being five days. Twelve patients had had vomiting, four noticed fever, and two complained of headache. Constipation was admitted by seven and diarrhoea by the same number. Sal. typhi infection was proved in four cases, being grown from intestinal contents in two, once from the blood and once by agglutination tests.

Examination of these patients was not consistently helpful; all were ill, half had a pyrexia of over $102^{\circ} \mathrm{F}$., 


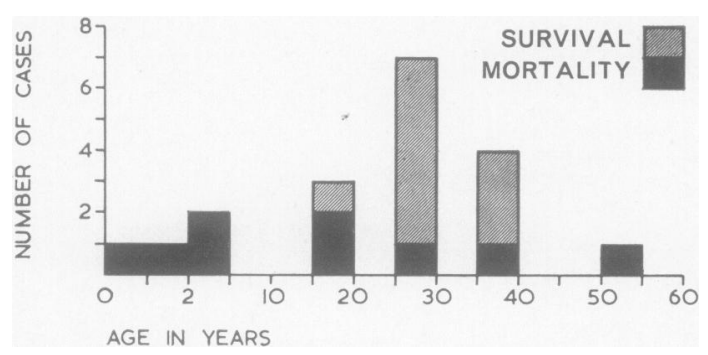

FIG. 9. Age and sex incidence of ileal perforation, with mortality. The first column in each ten-year period denotes female, the second male patients: most were young men.

and all were dehydrated. The abdomen was usually distended and could be very tender, with rebound pain, most felt in the right lower quadrant; or not tender at all, as was the case with the patient whose radiograph is shown in Figure 10. Radiographs always showed distended loops of small bowel,

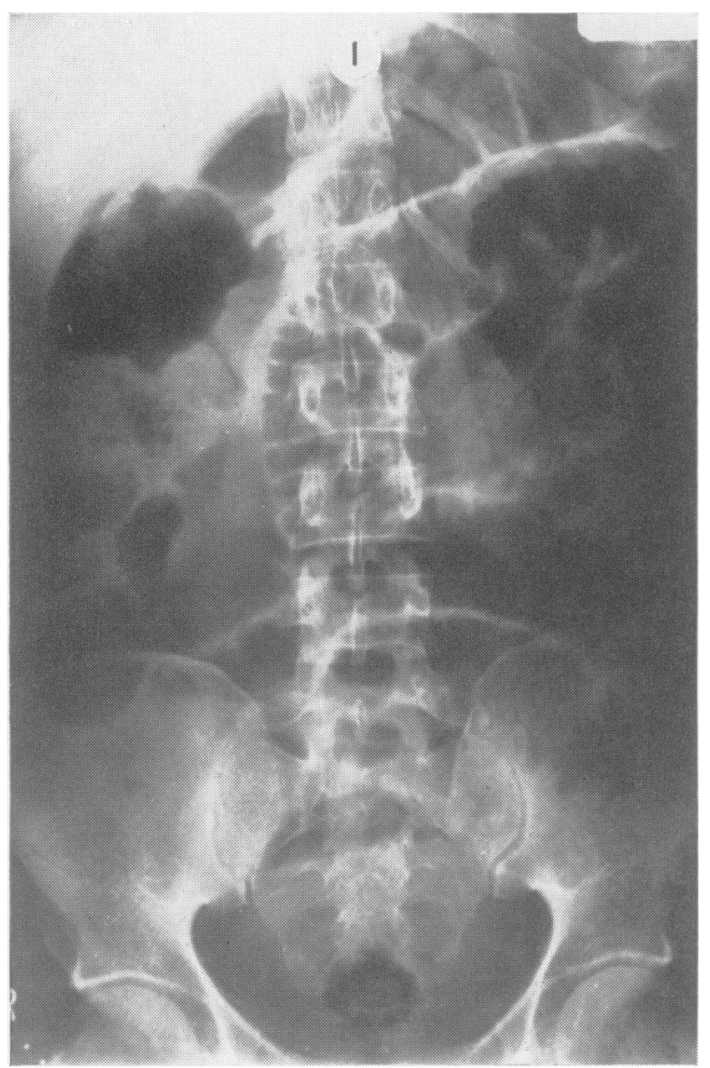

FIG. 10

FIG. 10. Plain supine radiograph of a patient suffering from ileal perforation: erect film showed fluid levels and no subphrenic gas. There is moderate layering. but appearances are in the main those of mechanical obstruction.

FIG. 11. Ileal perforation: there is a small amount of subphrenic gas on the right side. 
formation after surgery. Men in the third decade appeared to resist this illness most efficiently (Fig. 9), but outside this age group survival was a great deal less common.

The main problem with these patients has been that of diagnosis; clinically indistinguishable cases of appendicitis, adhesion obstruction, and septic ectopic pregnancy have been seen. A history of typhoid-like illness, proceeding suddenly to that of peritonitis has been rare indeed, but on careful questioning many patients did admit to a more vague illness, and less well-defined change of symptoms at the time of perforation, notably a change from diarrhoea to constipation. Headache is an unreliable finding in a country endemic for malaria, and is found in patients of all ages suffering a great variety of illnesses.

It has been found (Dickson and Cole, 1964) that this disease is almost certainly due in every case to typhoid ileitis, though the perforation takes place not at the start of the third week of illness, but at the end of the first or beginning of the second, and that the ascaris, though occasionally present in the peritoneal cavity, is equally certainly a secondary agent.

Typhoid toxaemia seemed to be the most important cause of death; in severe illness with many ulcers, surgery of any type, including resection of the whole affected ileum, was of no benefit: no patient with more than two perforations survived. All patients tolerated anaesthesia badly, so that the minimum of interference was undertaken. Undoubtedly, the main strength of treatment in this disease is chloramphenicol, in large and frequent doses.

\section{VOLVULUS}

At $4.3 \%$ of the series, volvulus was an unexpectedly small proportion; it formed a much larger part of the series from both Uganda (McAdam, 1961) and Rhodesia (White, 1961) and is a great deal more common still in Ghana, there affecting young and middle-aged men (Evans-Amfon, 1962).

Ages of the patients were 7 days to 40 years and volvulus involved the stomach (1), the large bowel (3), and the small bowel (15); with six deaths confined to the small bowel cases (Fig. 12). Of the small bowel series, three were jejunal and 12 ileal.

Nine were primary, and the lengths involved ranged from 6 in. to all but the upper $4 \mathrm{ft}$. of the small bowel: four of these patients died.

Three were secondary to a band; one to a loop of ileum loaded with roundworms: one associated with an absent right peritoneal cavity and malrotated right colon in a patient of 27 ; and one neonatal

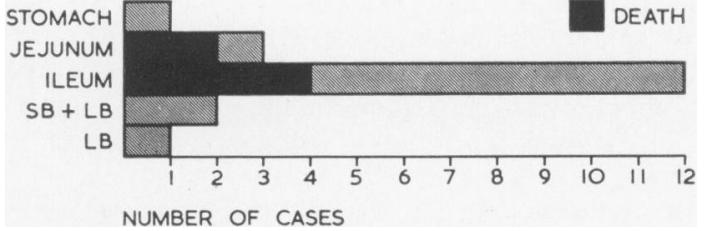

FIG. 12. Types of volvulus, with mortality.

type. There were two deaths, a female of 60 with adhesion volvulus, and an infant of 10 weeks with neonatal volvulus.

Three patients only had large bowel volvulus, and in two of these a length of ileum was included. The patient with uncomplicated sigmoid volvulus had had a week's symptoms. the others acute histories of four and nine hours. All survived resection.

\section{ASCARIS}

Twelve patients only were seen with symptoms of intestinal obstruction complicating what is possibly the commonest intestinal infestation in west Africa. Ages ranged from 4 to 30 years, and six patients were over 20: nine were females.

The average duration of symptoms was 40 hours; abdominal pain was the main complaint in every case, and was crampy and felt around the umbilicus. Vomiting was a symptom in nine, never severe, and was most marked at the onset of the illness. Constipation was present in five, and diarrhoea in two. Four patients admitted to having passed worms previously.

Temperatures were normal in two, raised but under $100^{\circ} \mathrm{F}$. in five and over $100^{\circ} \mathrm{F}$. in five. Tenderness of the abdomen was noted in eight, and rebound pain in three. A mass was palpable in the abdomen in six, and felt per rectum in one. At operation, a peritoneal exudate was noted in four cases.

Diagnosis was suggested by the mildness of the illness, the history, and age of the patient, which tended to be the same as that of caecocolic intussusception, the main differential. A mass when palpable was diagnostic, being usually in the ileum, but never being noted as crepitant. Abdominal tenderness and rebound pain were also suggestive. Radiographs showed distended loops of small bowel in every case in which they were taken, but only once demonstrated the bolus of worms. Ten patients underwent operation; the other two were diagnosed on the history and the presence of a mass in one, and the presence of roundworm bolus and distended small bowel loops on radiographs in the other. Both improved quickly with piperazine. At operation, two patients had no procedure, four had enterotomy 
and extraction of worms, and four massage of the worms into the caecum. All recovered quickly: of the enterostomy cases, one had wound spesis and another an incisional hernia. Piperazine was given to all patients after bowel sounds had returned to normal.

At least two distinct types of obstruction were observed in these patients.

OBTURATION Simple obturation was present in nine, and one boy had a closed loop between two large worms coiled two feet apart in the jejunum, the first at the duodenojejunal junction.

SPASM In two the obstruction was distal to the collection of worms, where a region of spasm of the bowel was present.

It is interesting that less than half of these patients were children, though they are usually associated with the disease. The illness was mild in all cases, and no somnolence or convulsions were noted.

The site of impaction (Fig. 13) was not confined to the terminal ileum, though the majority took place there: the highest impaction was at the duodenojejunal junction.

In the management of these patients it is felt that treatment should be conservative at first, provided the diagnosis is certain. At operation, if massage is impracticable, resection of the loop of bowel as advocated by Thomas is clearly preferable to enterotomy, as a quicker and cleaner procedure. Surgery can never cure ascariasis, but only disperse dangerous gatherings of worms: antehelmintics remain the main treatment of the disease.

\section{STENOSIS OF BOWEL}

Seven patients were placed in this rather heterogenous group, all diagnosed as having bowel strictures, though in three the exact lesion was not made clear.

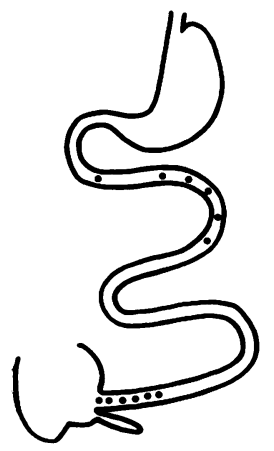

FIG. 13. See text.
Three patients had ileal stenosis following surgical relief of strangulated hernia, at three days, eight days, and 11 months after operation. One had ileal stenosis found at laparotomy; this was thought to be secondary to a volvulus at this site, which had reduced itself.

Two patients with jejunal stenosis presented, one the result of a non-specific inflammatory mass in the mesentery, and the other following two gastropexies: detailed information could not be obtained.

Only one patient with lymphopathia had a rectal stricture which caused obstruction: she was 60 years old, in very poor condition, and died a few hours after admission. Three of these seven patients had resection of bowel, and three by-pass operations, with three deaths. Analysis of this group is valueless; but it is probably worth noting that stenosis of the type named after Garre was seen three times in association with strangulated inguinal hernia in a period of five years during which over 150 such hernias were treated at University College Hospital, giving an incidence of $2 \%$ for this complication.

\section{UNKNOWN AETIOLOGY}

In six patients intestinal obstruction was diagnosed on a history of colicky abdominal pain, vomiting, and constipation, and the finding of distension; visible peristalsis was seen in three cases, and radiographs showed distended small bowel and fluid levels in one other. Two of these patients died within hours of admission, while the remaining four recovered with drip and suction. No diagnosis was made.

\section{CANCER}

Only five cases of intestinal obstruction due to cancer could be traced, and of these patients two were female. They were aged 36 and 53 years and had growths of the sigmoid and caecum respectively; the latter had caused an intussusception and this patient died after reduction thereof. Males were aged 22 with cancer of the rectum; aged 28 with carcinomatosis of origin in no defined area of the colon; and aged 41 with cancer of the sigmoid. Immediate mortality out of all five cases was two, and only the male with sigmoid growth had a resection, which was carried out in three stages.

As well as being a most uncommon cause of obstruction, at just over $1 \%$, the smallest of any series traced, cancer of the large bowel afflicted a very young group of people, all but one under 50 and three under 40 years old: it is unfortunate to record that not one of these patients had an operable growth. 


\section{TUBERCULOSIS}

Although this is a common disease of the respiratory system and spine in Nigeria, only three cases were recorded of its causing obstruction: the patients were aged 18,21 , and 26 years. The lesions were active tuberculous peritonitis, ileocaecal tuberculosis, and obstruction of the ileum by tuberculous glands. All cases had laparotomy, all were proven histologically, and all responded well to anti-tuberculosis drugs.

\section{APPENDICITIS}

A man of 50 presented a history of four days of lower abdominal pain with vomiting. His abdomen was distended and found at operation to contain an inflamed appendix and apparent obstruction of the terminal ileum; details were not given, but it is probable that this was only a localized adynamic ileus secondary to the appendicular infection.

\section{LIPOMA}

Another man of 50, suffering from upper abdominal pain and vomiting for seven days, was found to have a large lipoma of the mesentery of the upper jejunum, partially obstructing it: recovery quickly followed removal of the tumour.

\section{MESENTERIC THROMBOSIS}

This was recorded once, in a male of 60 , who gave a 12-hour history typical of this condition; at operation, most of the small bowel was ischaemic, and no procedure was undertaken. He died in three hours.

\section{RESECTION AND MORTALITY}

RESECTION The resection rates for the main diseases do not differ significantly from those in east Africa (McAdam, 1961), though it is the impression of surgeons practising in district hospitals in Nigeria that the resection rate for strangulated hernia is around $10 \%$. The rate for intussusception would be a great deal higher but for the large numbers of the caecocolic type; the figure for ileal perforation represents a plan of treatment rather than the absolute necessity for resection, as discussed above.

The necessity for resection has had the predictable effect on mortality (Fig. 14), and this is strikingly so with intussusception, where it involves a tenfold increase. The figure for hernia is about four times, and for adhesions less than twice. The reverse of expectation in volvulus is due to the unfortunate

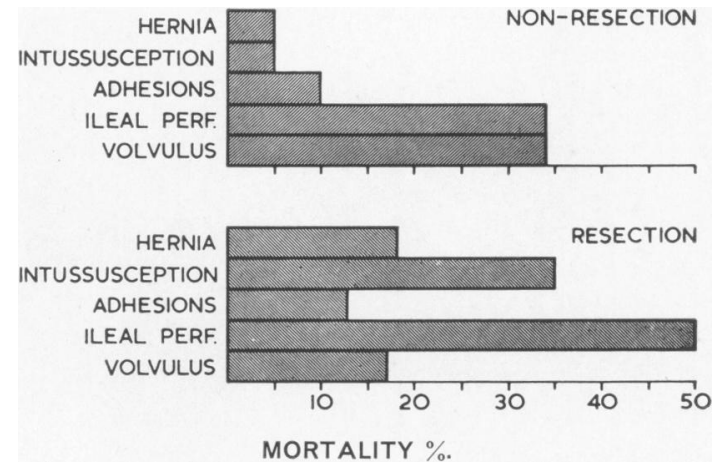

FIG. 14. The effect on mortality of the necessity for resection in the five main groups of diseases.

circumstances that in all the cases where death was associated with no resection, non-viable bowel was returned to the abdomen, either because the patient was considered to be too ill to stand a major procedure, or because it was not recognized at the time of operation.

MORTALITY The age incidence of mortality (Fig. 15) showed a grave proportion in the first two years of life, and a slowly rising rate with age, in spite of the decrease in incidence of obstruction after the fifth decade; the mortality among females at $21 \%$ was significantly higher than among males at $14 \%$, this imbalance being due to strangulated hernia. Congenital lesions giving rise to obstruction caused mortality of much greater proportions than any of the other main groups (Fig. 16), while the two immediate deaths due to cancer place this disease in a position of relative insignificance.

The overall average figure for the series was $16.1 \%$. This as a figure is of no special significance in comparison with other results either in the Tropics or temperate lands, as the pattern of the present series is so different from those in both. However, with the exclusion of both hernia and caecocolic intussusception, the figure is just over $37 \%$ which is markedly higher than others (Table III).

Only four diseases show a mortality of less than the average figure (Fig. 17), and of these, caecocolic intussusception and ascaris obstruction are notably benign illnesses giving a considerable restraining effect on the average results for the 436 patients.

The reasons for the grave mortality figures seem to be that congenital lesions were outstandingly lethal, for reasons already discussed; that ileal perforation has been included, and is also a severe illness; and possibly most important, that there has been a great deal of delay on the part of many patients in presenting for treatment, partly because 


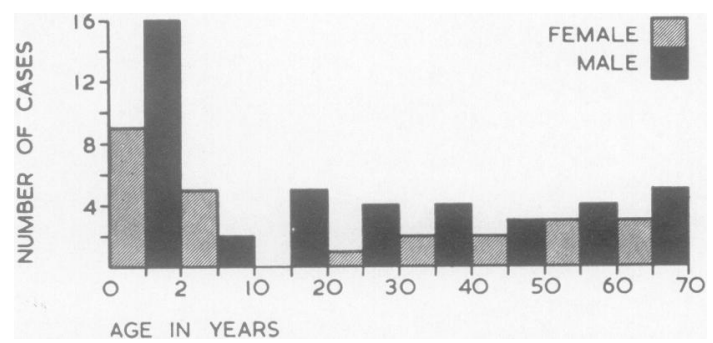

FIG. 15. The age and sex incidence of mortality for the series.

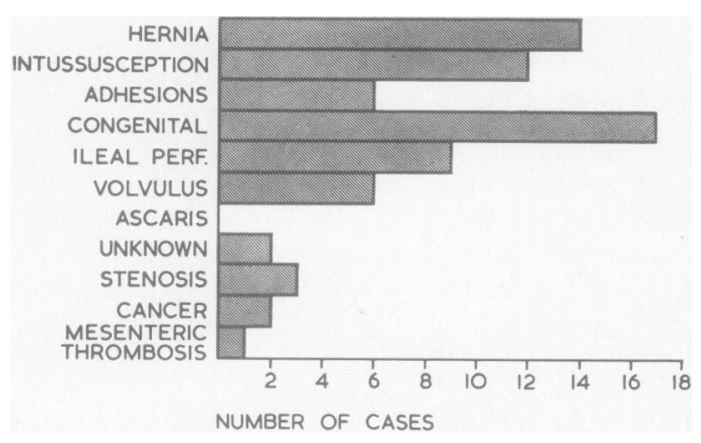

FIG. 16. The diseases and the number of deaths due to each.

\section{TABLE III}

COMPARISON OF MORTALITY FIGURES OF SEVERAL LARGE SERIES OF CASES OF INTESTINAL OBSTRUCTION

\begin{tabular}{ll} 
Series & Mortality (\%) \\
\hline Mulago & 6 (hernia plus volvulus were $90 \%$ of cases) \\
U.S.A.: & 6.9 \\
Minnesota & $9 \cdot 8$ \\
Pennsylvania & $12 \cdot 5$ \\
$\quad$ Massachusetts & 15 (excluding hernia: only $6.5 \%$ under 70 yr.) \\
London & 33 (excluding hernia) \\
Mpilo & 37 (excluding hernia and caecocolic \\
Ibadan & intussusception)
\end{tabular}

of distance, and partly because of reluctance to submit to modern hospital treatment, without having a try with more traditional methods first. Purging has appeared to play a major part in such treatment, and this, understandably, had done little to improve the condition of such patients in the first day or two of their illness.

McAdam (1961) has found mortality from strangulated hernia to be lower than usual in patients treated at Mulago Hospital in Uganda, and suggested three reasons for this:

1 Africans do not vomit as much as Europeans with the same illness: our experience has not given the impression that this is true of Nigerians, as the most severe grades of dehydration have been seen

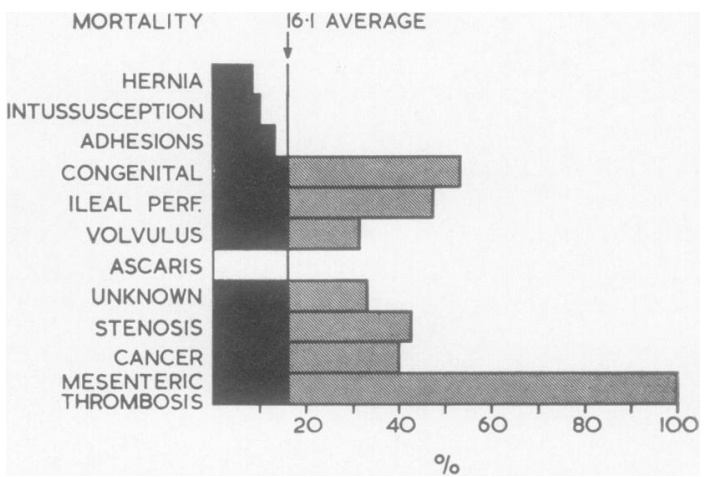

FIG. 17. Mortality of the various diseases in relation to the average for the whole series.

in these patients. It is the impression though that bowel activity returns to normal more quickly after resection or peritoneal sepsis.

2 Toxaemia is less in severity for a given illness in the African, or the same degree is better tolerated. With this it is not clearly possible to agree, on impression only; the mortality figures do not suggest any significant differences in Ibadan; and a study of the ileal perforations following typhoid ulceration (Dickson and Cole, 1964) has shown no significant difference in toleration of typhoid toxaemia from that recorded anywhere else.

3 The intestinal flora might be different in quality, due to the greatly increased carbohydrate/ protein ratio in the diet of the east African. The diet of the Nigerian is also largely carbohydrate, and extensive study is clearly required to find what the difference might be; the mortality with strangulation of bowel (Fig. 14) in the present series is again not significantly different, however, from that in other non-tropical series, and if the main factor in such mortality is toxaemia caused by resident intestinal bacteria, such a difference is not suggested in west African experience as it is in the east.

The management of intestinal obstruction demands the greatest concentration of judgment, experience, and skill; the part played by antibiotics is probably a great deal smaller than recognized, suggested by the finding of Nemir (1952) that there was no fall in the mortality due to this disease in Pennsylvania in the five years after the introduction of these agents compared with the previous five years. White (1961) stressed that the replacement of large quantities of fluids and delay in operation until balance in this and electrolytes has returned to normal has resulted in a pronounced fall in mortality, and the experience of the author in Nigeria has endorsed this entirely. For instance, the patient with 
herniation of 4 feet of ileum through a mesenteric defect was admitted in severe shock six hours after onset of the pain, and in the next six hours her blood pressure became unrecordable. From the operative findings it was clear that she had gangrenous bowel at this time, but blood and fluid transfusions, and hydrocortisone were given for 30 hours before operation was considered safe; and the postoperative course was at no time a cause for anxiety. The patients' history and clinical state have been the best guide to the amount and type of fluid required, and transfusions of the order of 4 litres of saline with or without potassium, in as many hours, have not given any signs of overloading in patients grossly lacking in extracellular fluid.

The 20 years between the ages of 15 and 35 years seem to be those of greatest natural resistance to the effects of obstruction, but even in these two decades there is no doubt that the outcome of treatment relates constantly to the period of illness before such treatment is started and that the main factor weighing against any operative ventures is simply the amount and type of fluids lost and deficient in that period; and the time spent in putting this right is of little importance, while the full replacement of these fluids is probably far and away the most significant part of the whole plan of treatment, after which the actual operation is merely a technical exercise.

There will always be mortality with intestinal obstruction, even if patients with unavoidable coincident disease are excluded. But, with a precisely planned programme of management, of which operation is by no means the most important part, it is felt that the present rate could be further lowered, especially combined with education to earlier attendance at hospital by these potentially gravely ill patients.

I wish to thank Professor W. W. Davey, who suggested this review, for constant advice and help in its preparation; and the staff of the Medical Illustrations Department at University Hospital, Ibadan, for preparation of the illustrations.

\section{BIBLIOGRAPHY}

INTESTINAL OBSTRUCTION

Andersen, D. A. (1956). Volvulus in Western India: a clinical study of 40 cases, with particular reference to the conservative treatment of pelvic colon volvulus. Brit. J. Surg., 44, 132-143.

Bowesman, C. (1952). Reduction of strangulated inguinal hernia. Lancet, 1, 882-823.

(1960). Surgery and Clinical Pathology in the Tropics, Livingstone, Edinburgh.

Bruusgaard, C. (1947). Volvulus of the sigmoid colon and its treatment. Surgery, 22, 466-478.

Kerr W. G., and Kirkaldy-Willis, W. H. (1946). Volvulus of the small intestine Brit. med. J., 1, 799-800.
Lowdon, A. G. R. (1951). Deflation of distended bowel at operation. Lancet, 1, 1103-1104.

McAdam, I. W. J. (1961). A three-year review of intestinal obstruction: Mulago Hospital, Kampala, Uganda. E. Afr. med. J., 38, 536-543.

McIver, M. A. (1932). Acute intestinal obstruction. II. Acute mechanical obstructions exclusive of those due to neoplasms and strangulated external hernias. Arch. Surg., 25, 1106-1124.

Nemir, P. (1952). Intestinal obstruction: ten-year statistical survey at the Hospital of the University of Pennsylvania. Ann. Surg., 135, 367-375.

Savage, P. T. (1960). The management of acute intestinal obstruction: a critical review of 179 personal cases. Brit. J. Surg., 47, 643-654.

Smith, G. A., Perry, J. F., Jr., and Yonehiro, E. G. (1955). Mechanical intestinal obstructions: a study of 1,252 cases. Surg. Gynec. Obstet., 100, 651-660.

Wangensteen, O. H. (1955). Intestinal Obstructions. Thomas, Springfield, Illinois.

White, A. (1961). Intestinal obstruction in the Rhodesian African: a review of 112 cases. E. Afr. med. J., 38, 525-535.

STRANGULATED HERNIA

Aird, I. (1957). A Companion in Surgical Studies, p. 642ff. Livingstone, Edinburgh.

Aung NYUNT, U. (1959). Annual review of surgical cases admitted and treated in Professor U Ba Thau's unit in the Rangoon General Hospital. Burma med. J., 7, 267-276.

Cole, G. J. (1964). Strangulated hernia in Ibadan: a survey of 165 patients. Trans. roy. Soc. trop. Med. Hyg., 58, no. 5, 441-447.

Davey, W. W. (1963). Personal communication.

Douglas, D. M. (1942). Strangulated hernia: a consideration of some factors affecting the mortality. Brit. med. J., 1, 354-357.

INTUSSUSCEPTION

Burkitt, D. P., Nelson, C. L., and Williams, E. H. (1963). Some geographical variations in disease pattern in East and Central Africa. E. Afr. med. J., 40, 1-6.

Cole, G. J. (1964). In the press.

Gillespie, C. E., and Moore, C. H. (1953). Acute abdominal emergencies in infancy and early childhood. Arch. Surg., 66, 741-751.

Joly, B. M., and Thomas, H. O. (1954). Non-infantile idiopathic intussusception in Western Nigeria (with a report of 33 cases). W. Afr. med. J., 3, 3-16.

Kark, A. E., and Rundle, W. J. (1960). The pattern of intussusception in Africans in Natal. Brit. J. Surg., 48, 296-309.

Kyle, J. (1954). Acute intussusception: review of 200 cases. Ulster med. J., 23, 117-123.

Majekodunmi, M. A. (1948). Acute intussusception. Brit. med. J., 2, 224.

Packard, G. B., and Allen, R. P. (1957). Results in the treatment of intussusception in infants and children. Surgery, 41, 567-575.

Roberts, K. D. (1950). Haustro-caecal invagination as a cause of intussusception. Brit. med. J., 1, 527.

Shove, R. F. (1950). Acute phlegmonous caecitis. Ibid., 1, 190.

ADHESIONS

Becker, W. F. (1952). Acute adhesive ileus: a study of 412 cases with particular reference to the abuse of tube decompression in treatment. Surg. Gynec. Obstet., 95, 472-476.

Dunkerley, G. E. (1953). Intestinal obstruction due to knotting of two loops of small intestine. Brit. J. Surg., 41, 66-70.

Noble, T. B. (1937). Plication of small intestine as prophylaxis against adhesions. Amer. J. Surg., 35, 41-44.

CONGENITAL

Cole, G. J. (1963). Congenital diaphragm in the upper rectum. Brit. J. Surg., 50, 523-524.

Gross, R. E. (1953). The Surgery of Infancy and Childhood. Saunders, Philadelphia.

Grove, L., and Rasmussen, E. (1950). Congenital atresia of the small intestine with a report of cases. Ann. Surg., 131, 869-878.

Haight, C. (1944). Congenital atresia of the esophagus with tracheoesophageal fistula. Ibid., 120, 623-655.

Keith, Sir A. (1908). Three demonstrations on malformations of the hind end of the body. Brit. med. J., 2, 1736-1741. 
Ladd, W. E. (1944). The surgical treatment of esophageal atresia and tracheoesophageal fistulas. New Engl. J. Med., 230, 625-637.

McPherson, A. G. (1963). Congenital anorectal anomalies. Brit. J. Surg., 50, 515-519.

Potts, W. J. (1950). Congenital atresia of the esophagus with tracheoesophageal fistula. J. thorac. Surg., 20, 671-680.

Swenson, O. (1948). The diagnosis and treatment of atresia of the esophagus and tracheoesophageal fistula. Pediatrics, 1, 195-204.

- (1958). Pediatric Surgery. Appleton, New York.

ILEAL PERFORATION

Conroy, J. V. (1957). The role of ascaris lumbricoides in intestinal perforations. Amer. J. Surg., 94, 542-545.

Dickson, J. A. S., and Cole, G. J. (1964). Perforation of the terminal ileum: a review of 38 cases. Brit. J. Surg., 51, 893-897.

Dunkerley, G. E. (1946). Perforation of the ileum in enteric fever: notes on 22 consecutive cases. Brit. med. J., 2, 454-457.

Evans-Amfon (1962). Personal communication.

Huckstep, R. L. (1960). Recent advances in the surgery of typhoid fever. Ann. roy. Coll. Surg. Engl., 26, 207-230.

Mehta, V. P. (1953). Intestinal perforation in enteric fever based on a study of 169 consecutive cases. Indian J. Surg., 15, 235-240.

volvulus

Bolt, D. E. (1956). The management of volvulus of the sigmoid colon. Brit. J. Surg., 44, 172-175.

Evans-Amfon (1962). Personal communication.

Isaacson, N. H., and Greer, D. B. (1952). The conservative treatment of the acute form of sigmoid volvulus. Surgery, 31, 544-551.
McAdam, I. W. J.(1961). A three year review of intestinal obstruction: Mulago Hospital, Kampala, Uganda. E. Afr. med. J., 38, 536-543.

McWalters, R. C. (1945). Volvulus of small intestine. Brit. med. J., 2, 626-627.

Rose, T. F. (1955). Volvulus of the small intestine with a normal mesentery: a review of 39 cases. Aust. N.Z. J. Surg., 25, 41-52.

Weeks, C. (1931). Volvulus of a sigmoid megacolon. Ann. Surg., 94, $1050-1060$.

White, A. (1961). Intestinal obstruction in the Rhodesian African: a review of 112 cases. E. Afr. med. J., 38, 525-535.

ASCARIS

Aiken, D. W., and Dickman, F. N. (1957). Surgery in obstruction of small intestine due to ascariasis. J. Amer. med. Ass., 164, 1317-1323.

Barber, F. (1947). Surgical aspects of roundworm disease. Brit. med. J., $1,49-50$.

Bogaert, W. (1951). Quelques considerations au sujet de l'ascaridiose. A propos d'un cas de perforation intestinale par ascaris. Ann. Soc. belge. Med. trop., 31, 303-306.

Conroy, J. V. (1957). The role of ascaris lumbricoides in intestinal perforations. Amer. J. Surg., 94, 542-545.

Herrick, C. A., and Emery, F. E. (1929). Changes in the tonicity of smooth muscle produced by toxins of ascaris lumbricoides. J. Pharmacol. exp. Ther., 35, 129-141.

Hoffmann, W. (1919). Askaridenilens mit besonderer Berücksichtigung des obturationsilens nebst Mitteilung von 7 Fällen. Mschr. Kinderheilk., 15, 199-231. 